\title{
Computer Network Simulation for Health Information Data Transmission at Medical Record Unit by Measuring Time Response
}

\author{
Puguh Yudho Trisnanto ${ }^{1}$, Arif Mulyadi ${ }^{2}$, Rizky Fadila ${ }^{3}$ \\ ${ }^{1}$ Program D-III Medical Record and Health Information, Malang State Health Polytechnics-Indonesia \\ ${ }^{2}$ Program D-III Nursing at Blitar, Malang State Health Polytechnics-Indonesia
}

\begin{abstract}
Computer network simulation of health information in the medical record transmission unit was conducted by measuring response time. Simulation time information was measured by recording reactions from start response time until finished. The response time from the server went to IP address allocation in one network. By using DHCP method, the simulation of IP Address which is formed according to the simulation of e-mail delivery network include: Building $B, C$ and $D$ by using IP Address: 200.100.10.1 class $C$ which was used for medium sized network and joined by the POP3 protocol (Post Office Protocol) protocol server. By using standard reactions time it was categorized as follows: the reaction rate should be $\leq 8$ seconds, the reaction speed was measured as the user presses the "submit" button to the system and starts the reaction to be $\leq 8$ seconds and the reaction speed was measured as the user presses the "submit" button to the system and initiates the reaction should be: a). Maximum $\leq 30$ seconds b). Average $\leq 6$ seconds. The reaction speed was measured as the user presses the "submit" button to the system and initiates the reaction should be: a). 95 percent $\leq 8$ seconds b). 100 percent $\leq 30$ seconds For calculation of response time taken from the average reaction speed per module from Building $B$, $C$, and $D$. So as to produce the delivery of protocol packet according to the initial design of data obtained: Average $\leq 6$ seconds (unaccepted Variable), 100 percentile $\leq 8$ seconds (receiver / variable), and 100 percent $\leq 30$ seconds (accepted / variable).
\end{abstract}

Keywords: response; time; network , DHCP; POP3

\section{Background}

Delivery of health information data related to information or via e-mail is a needs at this time in the Medical Record Unit because the technology used is adapted to the educational level of human resources needs to use. This should be known by the management of RS to create simulation data of health information in accordance with the Unit in need other than the information. Capital budgets used should be sufficient to create a simulation of health information data. Simulation project system in the form of a simulation project data system for health information is essential prior to the implementation of activities that actually do this that is not widely known by the hospital management to make the design of the data of health information that is used by the Unit related to infrastructure in accordance with the data requirements of health information required. In the absence of a project design, simulations of health information data will swell the costs and incompatibility of the needs of the equipment used will lead to health data information that is not in accordance with the needs of user and management will often evaluate the needs used in accordance with the replanning. The cost and time will be re-issued to make the health information data system connected in accordance with the return needs. If this happens continuously, it will cause friction with other management. Simulation of health information data is the main thing need to be done by the hospital management to know the effectiveness of the system using computer network related to IP Address, cable connections and other design of network construction. The following computer network simulation design uses a star network topology with DHCP method.

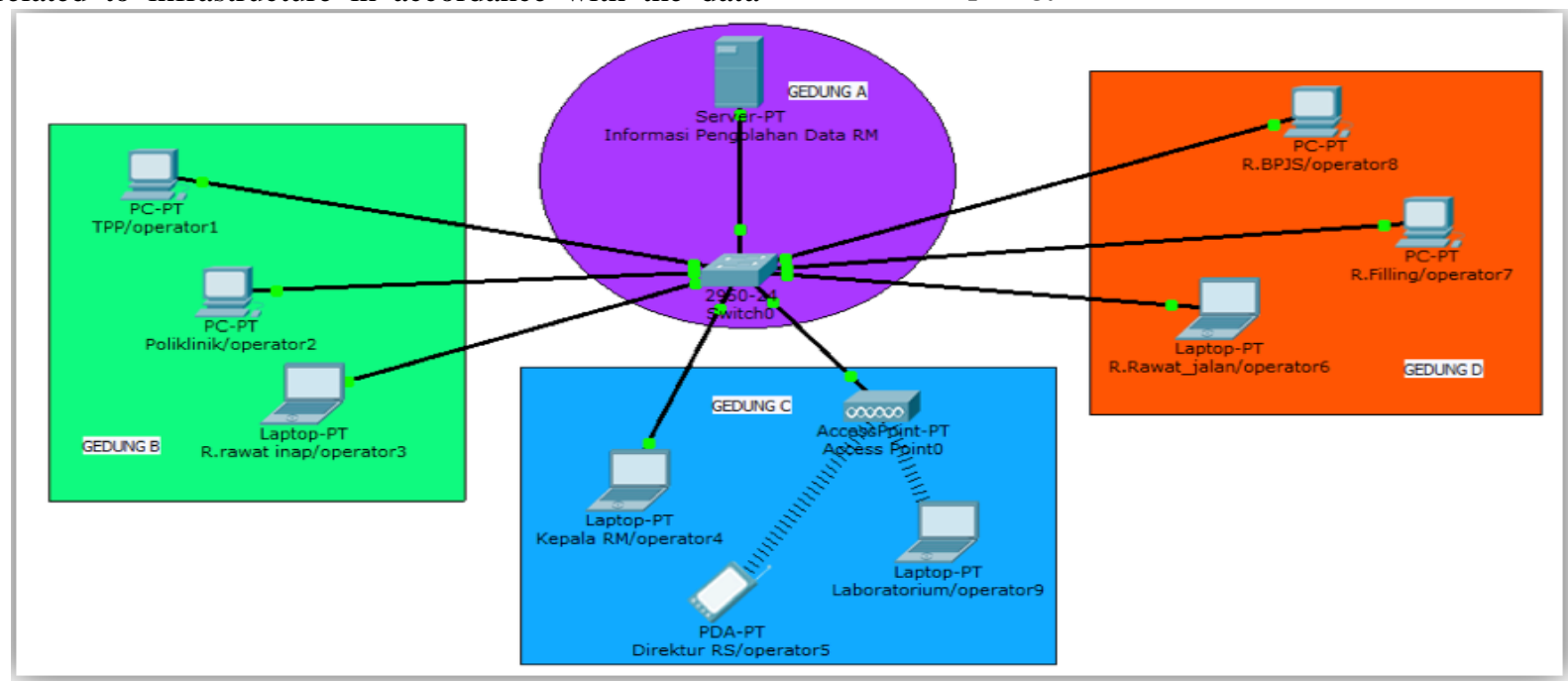

Figure 1: Interface Design Star Network Topology

Volume 6 Issue 7, July 2017 www.ijsr.net 


\section{International Journal of Science and Research (IJSR) \\ ISSN (Online): 2319-7064}

Index Copernicus Value (2015): 78.96 | Impact Factor (2015): 6.391

The interface design of the Star Network Topology of the image lays out a network design construct consisting of 4 interconnected buildings using Swicht and Access Point which aims to know the extent to which health information data is transmitted when done using the Star Network topology method. Computer network simulation is done by network map which will be used by grouping into 4 Building, Building A as unit (Information Data Management RM), Building B consists of TPP unit, Polyclinic, R. inpatient, Building $\mathrm{C}$ as manager or decision maker From the Director of RS, RM Head and Laboratory, Building D as a storage center connected with financial management consists of: R.BPJS, R.Filling and R. Inpatient. Map interface data communication has been done. Support equipment prepared by placing switch 2960/24 type which consists of 24 internal ports for connecting Building A, Building B, Building $\mathrm{C}$ and Building D. Ports used Fast Ethernet 0/1 link up to use the server, FastEthernet 0/2 link up used PC / TPP, FastEthernet 0/3 link up to use PC / Polyclinic, FastEthernet $0 / 4$ link up to use PC / hospitalization, Wireless 0 links up to use PDA / Director, FastEthernet 0/5 link up used Laptop / Chief RM, FastEthernet 0 / 6 link up used PC / R.BPJS, FastEthernet 0/7 link up used PC / R.Filling, FastEthernet 0/8 link up used Laptop / R.Rawat_jalan, FastEthernet 0/9 link up used Laptop / Laboratory. Cabel connections used CST (Copper Straight-Through). The simulation network design results have functioned well with the green indicator light on.

\section{Method}

Figure 2: Detailed Response Time (Laird \& Brennan, 2006)

Figure above set 2 (Two) potentials at reaction speed, both initiated when the user presses the button "submit" while others finishing process when the system begins respond and others complete. Note the specification for the speed of the reaction: [1]. Reaction speed must be $\leq 8$ seconds. [2]. The reaction speed is measured since the user presses the "submit" to system and start the reaction should be $\leq 8$ seconds. [3]. The reaction speed is measured since the user presses the "submit" to System and start the reaction should be: a). Maximum $\leq 30$ seconds b). On average $\leq 6$ seconds [4]. The reaction speed is measured since the user presses to button "submit" to System and start the reaction should be: a). 95 percent $\leq 8$ seconds b). 100 percent $\leq 30$ seconds For the calculation of the response time is taken from the average speed Reaction per module between user and system.

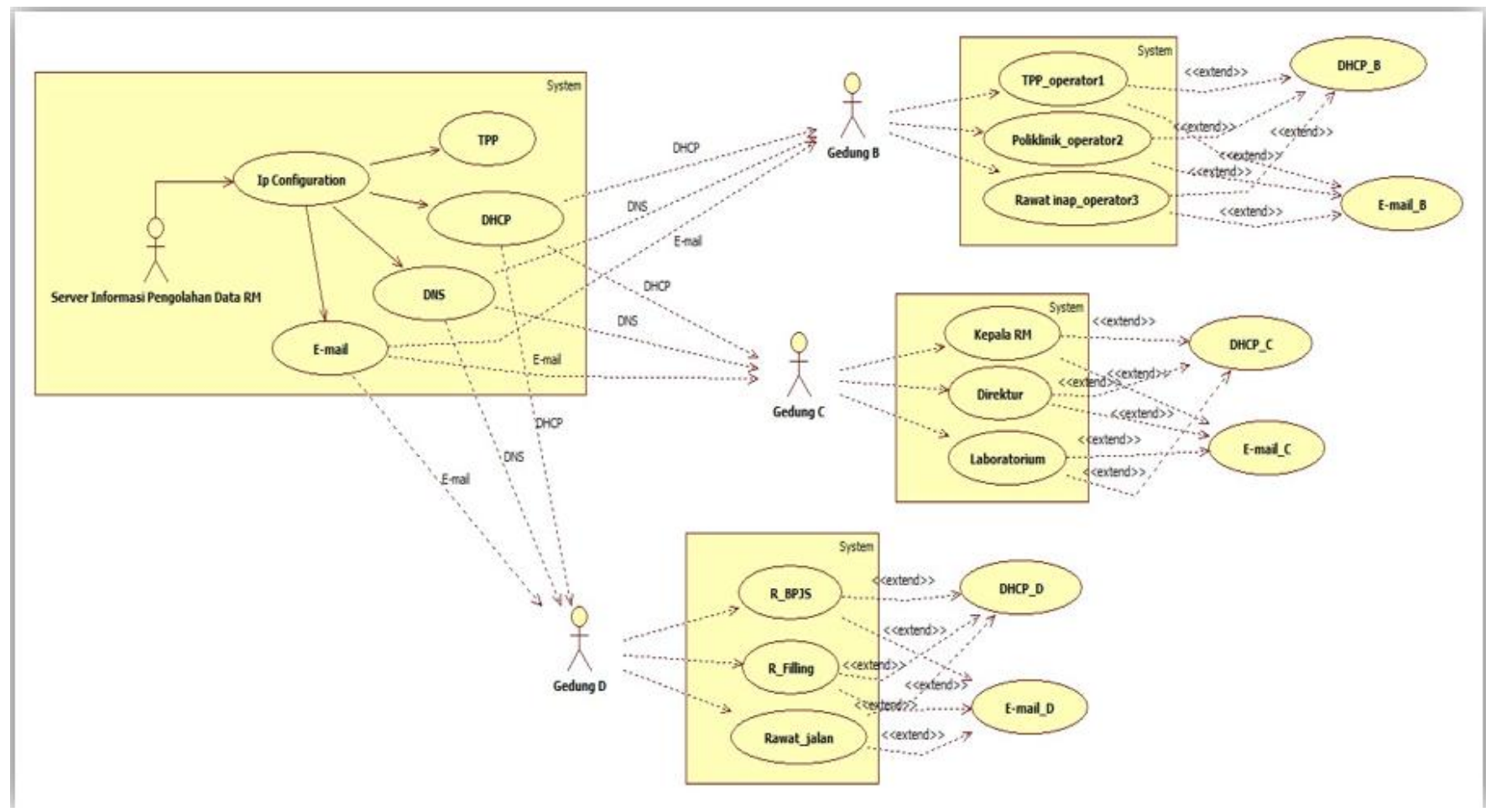

Figure 3: Use Case Diagram (Dynamic Host Configuration Protocol)

Stages use DHCP (Dynamic Host Configuration Protocol). This method stages portrait DHCP process performed on the image process method that was performed in the end of DHCP server data management information, using IP configurations in the main server includes. This includes IP,
DHCP, DNS and E-mail so that produce rational design of the system in the form of conceptual design system using case diagram with the interaction between the actors and the system. The use of case DHCP, DNS, and E-mail depend on the connections to the $\mathrm{B}$ automatically from the primary

\section{Volume 6 Issue 7, July 2017 www.ijsr.net}




\section{International Journal of Science and Research (IJSR) \\ ISSN (Online): 2319-7064}

Index Copernicus Value (2015): 78.96 | Impact Factor (2015): 6.391

server. Dependency itself is information stand alone and in interacted to use case TPP and polyclinics. Hospitalizations by generating connections extends in the form DHCP_B and e-mail_B, connections extend portrait of the information will stop at the destination use last case of actor at building B TPP, polyclinics and Inpatient. DHCP, DNS, and E-mail using connections Dependency to building $\mathrm{C}$ automatically from the main server. Dependencies alone are stand-alone information and interacted to the Head of Unit, Director, and laboratories by generating Extension connections in the form of DHCP_C and e-mail_C, Extend connections describe stop information in the last use case purpose of the building actor C Head of Unit, Director, And Laboratory. Use case DHCP, DNS, and E-mail using connections Dependency to building $\mathrm{D}$ automatically from the main server. Dependency itself is stand-alone information and interacted to use R.BPJS, R.Filling and outpatient by generating Extension connections in the form of DHCP_D and e-mail_D, Extend connections describe stop information in the last use case purpose of building actor D R.BPJS , R.Filling and Outpatient.

\section{Results}

This part aims to identify the components Gambar.3.1 implementation. Table Stages DHCP (Dynamic Host Configuration Protocol), and Figure 3.2. Output results table POP protocol 3. From both results are in end server devices as the primary data manager with the output information output in the form of packets POP3 (Post Office Protocol), which dijela scan in the form of Stages DHCP and POP3 table as follows:

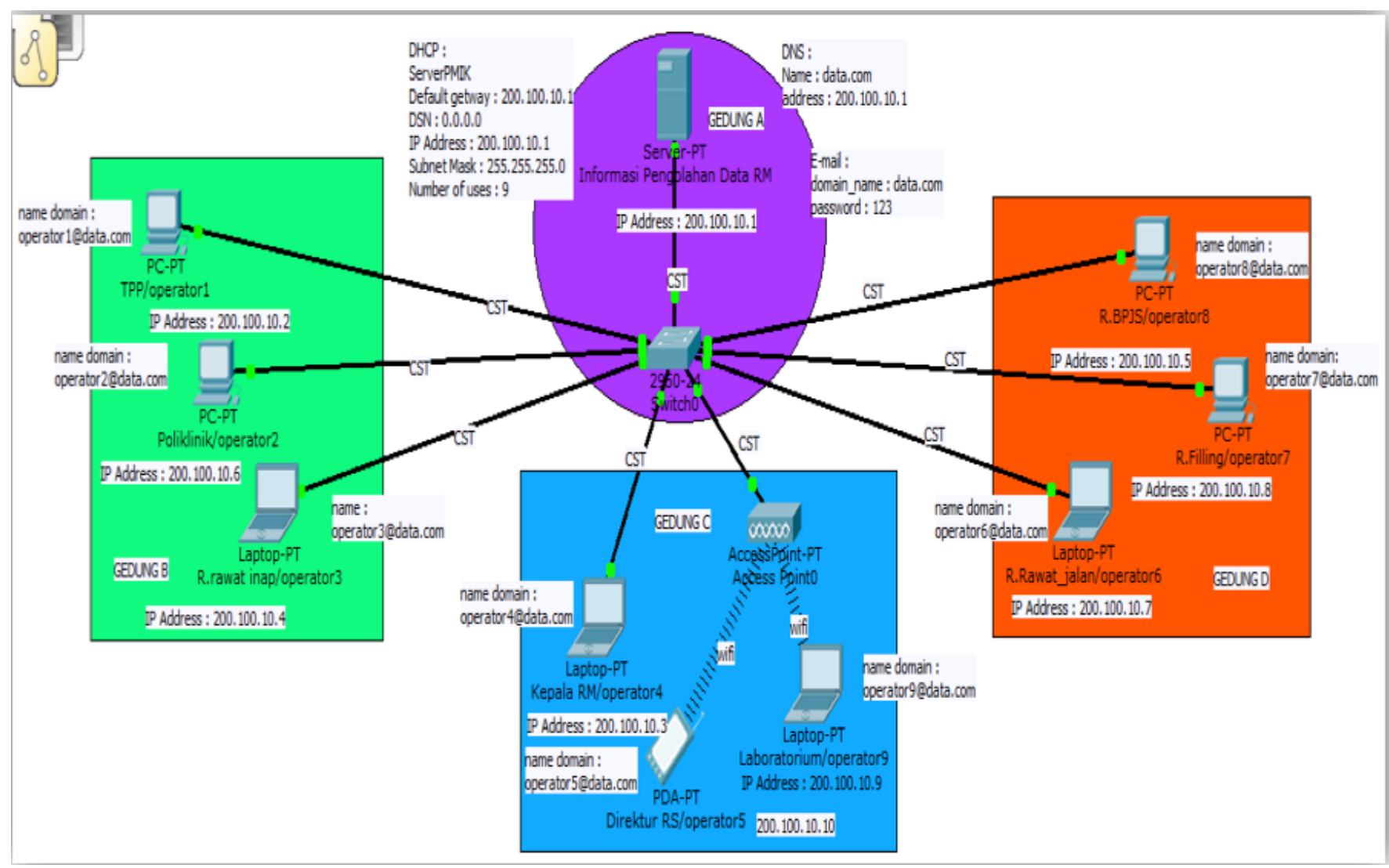

Figure 4: Stages of DHCP (Dynamic Host Configuration Protocol)

The results of the IP configuration This phase aims to determine the components of the implementation of the IP configuration of end devices starting consists of Building A Server-PT Information Data Processing, and Switch1 Building B PC-PT TPP / operator1, PC-PT Polyclinics / operator2, Laptop-PT inpatient / operator3, Building C-PT Access Point Access Point0, Laptop-PT Chief RM / operator4, SMARTPHONE-PT Director RS / operator5, and Laptop-PT Lab / operator 9. Building D PC-PT R.BPJS / operator8, PC-PT Filling / operator7, Laptop-PT R.Outpatient / operator6. Cables used from each building using CST cable (Straight-Through Copper). IP Address 200.100.10.1 C Class IP address C Consists of 24 bits for the network ID and the remaining 8 bits are used for the host ID, so the class C IP address is used for small / medium sized networks used by the server. For IP addresses in buildings B, C, and D use the DHCP method in each IP Address Medical Record configuration. Next include the DNS configuration with the name data.com as the domain name Simultaneous delivery of e-mails in each medical record unit. Configure e-mail clarifies the information component in the method e-mail by filling out the user: the operator name 1,2,3,4,5,6,7,8 and 9 the name of the password: 123 respectively operator name as in with Figure.3. Table Stages DHCP (Dynamic Host Configuration Protocol) Accompanied by unit and description of the building. The next phase of the output sending e-mail to each unit associated with the use of packet data transmission protocol with name POP3 (Post Office Protocol)

Which is described with the following table:

Volume 6 Issue 7, July 2017 www.ijsr.net

Licensed Under Creative Commons Attribution CC BY 


\section{International Journal of Science and Research (IJSR) ISSN (Online): 2319-7064}

Index Copernicus Value (2015): 78.96 | Impact Factor (2015): 6.391

\begin{tabular}{|c|c|c|c|c|c|}
\hline $\begin{array}{c}\text { End } \\
\text { Devices_1 }\end{array}$ & $\begin{array}{c}\text { End } \\
\text { Devices_2 }\end{array}$ & To & Protocol & Ket_send & $\begin{array}{c}\text { Unit_prefer / } \\
\text { Building }\end{array}$ \\
\hline TPP & R.BPJS & Operator8@ data.com & POP3 (Post Office Protocol) & Succes & TPP / Building B \\
\hline Polyclinic & R.Filling & Operator 7 @ data.com & POP3 (Post Office Protocol) & Succes & Polyclinic / Building B \\
\hline Head RM & R.Outpatient & Operator 6 @ data.com & POP3 (Post Office Protocol) & Succes & Head of RM / Building C \\
\hline Director of RS & R.BPJS & Operator8 @ data.com & POP3 (Post Office Protocol) & Succes & Director RS / Building C \\
\hline Laboratory & Polyclinic & Operator 7 @ data.com & POP3 (Post Office Protocol) & Success & Laboratory / Building C \\
\hline R.BPJS & Head Unit & Operator 4 @ data.com & POP3 (Post Office Protocol) & Success & RBPJS / Building D \\
\hline R.Filling & Director of Hospital & Operator 5 @ data.com & POP3 (Post Office Protocol) & Success & Filling / Building D \\
\hline R.Outpatient & TPP & Operator 1 @ data.com & POP3 (Post Office Protocol) & Success & R.Outpatient / building D \\
\hline \multicolumn{7}{|c}{ Figure 5: Output Table results POP3 protocol }
\end{tabular}

The results of the analysis table 3.2. is the result of mapping the output information e-mail delivery of end to end devices 1 devices 2 the user with the name of the destination information operator1@data.com with packet delivery protocol POP3 (Post Office Protocol), send information success and information sender unit. Here's an explanatory mapping for simulating the delivery of POP3 protocol packets to each of the intended units: [1]. TPP unit to unit with the destination user R.BPJS operator8@data.com with POP3 protocol packets, information sent from the information Success Building B TPP unit. [2]. Polyclinic unit to unit with the destination user R.Filling operator7@data.com with POP3 protocol packets, information sent from the information Success Building B unit hospitalization. [3]. Head Unit RM outpatient unit to the destination user operator6@data.com with POP3 protocol packets, information sent from the information Success Building C unit Head of RM. [4]. Unit Director RS to R.BPJS with destination user operator8@data.com with POP3 protocol packets, information sent from the information Success Building C unit director. [5]. Laboratory to the clinic with destination user operator7@data.com with POP3 protocol packets, information sent from the information Success Building $C$ laboratory unit. [6]. RM R.BPJS unit to head to the destination user operator4@data.com with POP3 protocol packets, caption information sent from Building D Success R.BPJS unit. [7]. Filling Unit to the Director of the destination user operator5@data.com with POP3 protocol packets, caption information sent from Building D Success Filling unit. [8]. Polyclinic unit to unit R outpatient TPP to the destination user operator1@data.com with POP3 protocol packets, information sent from the information Success Outpatient Building D unit.

\section{Discussion}

Diagram analysis sequence time e-mail delivery, the results of this analysis are taken from the Gambar.3.1. Table Stages DHCP (Dynamic Host Configuration Protocol), Gambar.3.2 Output Table results POP3 protocol to provide time description conducted in accordance with the specifications for the speed of the reaction: [1]. The reaction rate should be $\leq 8$ seconds. [2]. The reaction speed is measured since the user presses the "submit" into the system and start the reaction must $\leq 8$ seconds. [3]. The reaction speed is measured since the user presses the "submit" into the system and start the reaction should be: a). Maximum $\leq 30$ seconds b). Average $\leq 6$ seconds [4]. The reaction speed is measured since the user presses the "submit" into the system and start the reaction should be: a). 95 percentile $\leq 8$ seconds b). 100 percentile $\leq 30$ seconds response time taken for the calculation of the average speed per module reaction between user and system (Laird \& Brennan, 2006). Results of the discussion of Gambar.4.1. Sequence Diagram Analysis of e-mail delivery time, according to the results system reaction speed system response to the final results obtained for the reaction speed of the system $\leq 8$ seconds starting from Building B, C, and D produces 0,001 times for all the initial time in the respective reactions each building so that the acquired time information is received / variable. The reaction speed is measured since the user presses the "submit" to the system with time average $\leq 6$ seconds denied the information generated captions / do not variable this is because there are 4 four of objective data exceeding email Maximum time $\leq 30$ seconds including : [ 1]. Unit polyclinic to R. Filling with reactions time 10:52:34 sec, [2]. Unit R.BPJS to RM Head with reactions time 11:03:33 sec, [3]. Unit $\mathrm{R}$ outpatient reactions to TPP with time 11:06:46 seconds, [4]. Unit $\mathrm{R}$ inpatient to Outpatient with reactions time 18:41:33 $\mathrm{sec}$. So that the total average $\leq 6$ seconds 13.62 seconds. Although this data is rejected / do not variable, in an analysis diagram caused by sequence stimulus into the information delivery connections devices switch which is a port switching interface 24 which connected to PCs and laptops as well as the access point. With a range of time division which automatically in the simulation done by system.

\section{Conclusion}

By using DHCP that the IP Address set up simulations to be easily used by the user in accordance with the simulation of e-mail delivery network include: Building B, C and D by using IP Address: 200.100.10.1 class C that use the POP3 protocol ( Post Office Protocol). Packet delivery protocol was in accordance with the initial design simulation computer network data transmission of health information in medical records with methods measuring response time with data obtained: average $\leq 6$ seconds ( not variable), 100 percent $\leq 8$ seconds (accepted/ variable), and the 100 percent $\leq 30$ seconds (accepted / variable)

\section{References}

[1] Aladwani, A. M; dan Palvia, P. C. 2002. Developing and Validating an Instrument for Measuring User Perceived Web Quality. Information dan Management, 39 (6), 467-476.

[2] Puguh Yudho,T. 2016. Perancangan sistem informasi laboratorium komputer pada Program studi D-III pmik 


\section{International Journal of Science and Research (IJSR) \\ ISSN (Online): 2319-7064}

Index Copernicus Value (2015): 78.96 | Impact Factor (2015): 6.391

poltekkes kemenkes malang. Malang: Jurnal Pendidikan Univesitas Negeri MalangVol.1,No.11:2152-2157

[3] Gramus, D. dan Herron, D., 1996, Measuring the Software Process - A Practical Guide to Functional Measurements, Yourdon Press, Prentice Hall, New Jersey, US

[4] Jogiyanto. 2011. Konsep dan Aplikasi Structural Equation Modeling berbasis Varian dalam Penelitian Bisnis. UPP STIM YKPN: Yogyakarta.

[5] Hidayah, N., Kumaidi, \& Kartowagiran, B. (2015). Integrated model of one parameter logistic model and response time model. In Prosiding, International Conference and Workshop on Basic and Applied Sciences. Surabaya: Universitas Airlangga.

[6] John Burch, dan Gary Grudnitski.1986. Information Systems Theory and Practice. New York : John Wiley, and Sons.

[7] Hornke, L. F. (2000). Response times in CAT as an additional means to differential assessment. Psicológica, 21(1), 175-189. Retrieved from https://www.uv.es/psicologica/articulos1y2.00/hornke.p df

[8] Ingrisone II, J. N. (2008). Modeling the joint distribution of response accuracy and response time. Disertasi, tidak dipublikasikan. Florida State University.

[9] Gvozdenko, E., \& Chambers, D. (2007). Beyond test accuracy: Benefits of measuring response time in computerised testing. Australasian Journal of Educational Technology, 23(4), 542-558. Retrieved from http://dx.doi.org/10.14742/ajet.1251

[10] Meyer, J. P., \& Wise, S. L. (2005). Item response timeand distractor analysis including item response time in distractoranalysis via multivariate kernel smooting. Makalah disajikan dalam The meeting of the National Council on Measurement in Education.

Volume 6 Issue 7, July 2017 www.ijsr.net 